\title{
Production of proteins in Bacillus subtilis can be improved by engineering components affecting posttranslocational protein folding and degradation
}

\author{
Marika Vitikainen*, Hanne-Leena Hyyryläinen, Anna Kivimäki, \\ Vesa P Kontinen and Matti Sarvas
}

Address: Laboratory of Infection Pathogenesis, National Public Health Institute, Mannerheimintie 166, FIN-00300 Helsinki, Finland

* Corresponding author

\author{
from The 4th Recombinant Protein Production Meeting: a comparative view on host physiology \\ Barcelona, Spain. 2I-23 September 2006 \\ Published: 10 October 2006 \\ Microbial Cell Factories 2006, 5(Suppl I):P20 doi:10.II86/I475-2859-5-SI-P20
}

(C) 2006 Vitikainen et al; licensee BioMed Central Ltd.

\section{Background}

Bacillus species have a high capacity to secrete their own proteins into the extracellular medium and are therefore considered as attractive hosts for producing heterologous proteins. However, the secretion is often inefficient suggesting that there are bottlenecks in the secretion pathway. This research focuses on the posttranslocational events in protein secretion. Three putative bottleneck components (see Results) affecting the extracytoplasmic protein folding and degradation were genetically engineered and the effects on the protein secretion were studied [1].

Currently we are participating in EuroSCOPE program on Science of Protein Production for Functional and Structural Analysis. The project will continue to further develop and exploit $B$. subtilis as a host especially for the production of protein complexes and membrane proteins. The aim is to find out balanced sets of quality control and protein folding factors to be able to optimise protein production. In the EuroSCOPE program membrane proteins of $B$. subtilis as well as gram-positive pathogen representing potential vaccines and targets for novel antimicrobial drugs are used as model proteins. The project has been initiated by producing a membrane protein B. subtilis, histidine kinase $\mathrm{YxdK}$.

\section{Results}

The first component modulated is the amount of PrsA lipoprotein on the outer surface of the cytoplasmic mem- brane. PrsA is an essential membrane-bound folding factor with peptidyl prolyl isomerase activity. Previous studies have identified that secretion of some exoproteins is dependent on the PrsA lipoprotein. Dependency of model proteins on the PrsA was studied by lowering the PrsA level below the wild type level. The effect of PrsA overproduction was also investigated. The second component is the increase of the net negative charge of the cell wall generated by mutating the dlt operon and consequently preventing the D-alanine substitution of anionic cell wall polymers. The third component modulated is the level of HtrA-type quality control proteases at the membrane-cell wall interface that serve as cleaning proteases to degrade accumulated and misfolded proteins. The effect on the secretion of 11 industrically interesting heterologous proteins was studied by western blotting and enzymatic assays [1]. The results are shown in table 1 . The secretion of four of proteins was dependent on the PrsA lipoprotein and the overproduction of PrsA enhanced the secretion of two of them, $\alpha$-amylase of $B$. stearothermophilus (4-fold) and pneumolysin (1.5-fold). The mutation in the dlt operon enhances the secretion of one protein, pneumolysin, about 1.5-fold. Decreasing the level of HtrA proteases caused harmful effects on growth and did not enhance secretion. Pertussis toxin subunit S1 was found to be a substrate for HtrA-type proteases and its secretion was dependent on these proteases. 
Table I: Effect of PrsA, dlt mutation and depletion of HtrA proteases on secretion of heterologous proteins studied.

\begin{tabular}{|c|c|c|c|c|}
\hline Protein and origin & PrsA dependency & PrsA Over- expression & Dlt mutation & Depletion of HtrA protease \\
\hline$\alpha$-amylase (B. stearothetmophilus) & yes $(+)$ & $\uparrow$ & no effect & $\downarrow$ \\
\hline$\beta$-glucanase (B. licheniformis) & no & & no effect & \\
\hline Penicillinase (B. licheniformis) & no & & no effect & no effect \\
\hline Pneumolysin (S. pneumoniae) & yes $(+)$ & $\uparrow$ & $\uparrow$ & $\downarrow$ \\
\hline Diphteria toksoid (C. diphteriae) & no & no effect & & \\
\hline Staphylokinase (S. aureus) & yes(-) & & & \\
\hline Pectinase (E. carotovora) & yes $(+)$ & $\downarrow$ & $\downarrow$ & no effect \\
\hline Pectin methylesterase (E. chrysanthemi) & no & & no effect & no effect \\
\hline$\beta$-lactamase $(E$. coli $)$ & yes $(+)$ & no effect & $\downarrow$ & \\
\hline Pertussis toxin SI (B. pertussis) & no & $\downarrow$ & $\downarrow$ & $\downarrow$ \\
\hline Pertussis toxin S4 (B. pertussis) & no & & & \\
\hline
\end{tabular}

yes(+), positive dependency, yes(-) negative dependency, $\uparrow$, increase in secretion and $\downarrow$, decrease in secretion.

\section{Conclusion}

In this research a fairly large number of model proteins were used allowing us to make more general conclusions on how secretion of heterologous protein in B. subtilis can be improved. Results indicate that some heterologous proteins are secreted at enhanced levels when components involved in the late stages of protein secretion are modulated. PrsA lipoprotein and its overproduction are good candidates to be tested when optimising the secretion of an exoprotein in B. subtilis. Modulation of the net charge of the cell wall may also have role in biotechnological applications. However lowering the level of HtrA proteases does not seem to be a means to enhance protein secretion.

\section{References}

I. Vitikainen M, Hyyryläinen HL, Kivimäki A, Kontinen VP, Sarvas M: Secretion of heterologous proteins in Bacillus subtilis can be improved by engineering cell components affecting posttranslocational protein folding and degradation. J Appl Microbiol 2005, 99:363-375.
Publish with Biomed Central and every scientist can read your work free of charge

"BioMed Central will be the most significant development for disseminating the results of biomedical research in our lifetime. "

Sir Paul Nurse, Cancer Research UK

Your research papers will be:

- available free of charge to the entire biomedical community

- peer reviewed and published immediately upon acceptance

- cited in PubMed and archived on PubMed Central

- yours - you keep the copyright

Submit your manuscript here:

http://www.biomedcentral.com/info/publishing_adv.asp 